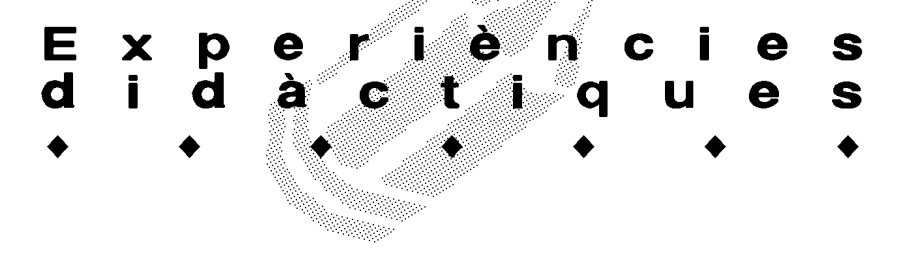

\title{
IDEES ALTERNATIVES SOBRE L'ALIMENTACIÓ EN ALUMNES PORTUGUESOS D'ENSENYAMENT BÀSIC (11-12 ANYS)
}

\author{
Vítor Martins da Silva. Mestre d'Ensenyament Bàsic a Beja. Portugal. \\ Vicente Mellado Jiménez i Constantino Ruiz Macías. Àrea de Didàctica de les Ciències Experimentals. \\ Universitat d'Extremadura.
}

Aquest treball ha estat parcialment subvencionat pel "Proyecto de Investigación 2PR0A100" de la "Consejería de Educación, Ciencia y Tecnología" de la Junta d'Extremadura, i forma part d'una investigació més àmplia en la qual el coneixement de les idees de l'alumnat només és el primer pas perquè els professors realitzin una reflexió metacognitiva sobre la seva pràctica docent a l'aula, i elaborin i avaluïn propostes d'ensenyament enfocades a aconseguir l'evolució conceptual dels alumnes en aquest tema.

\section{Introducció}

Nombrosos estudis ens indiquen que existeix un creixent augment dels problemes de salut relacionats amb l'estil de vida. Això vol dir que la salut d'una població no dependrà, només, dels avenços encaminats a la restauració i la prevenció de la salut, a través dels sistemes d'assistència sanitària. La prevenció de la salut s'entén com aquells actes organitzats pels sistemes d'assistència sanitària per tal d'evitar l'aparició de determinades patalogies en la població. Fem aquest aclariment atès que moltes persones confonen la prevenció de la salut amb l'educació per a la salut.

Una part important de la salut d'un poble dependrà dels estils de vida, i aquests depenen en gran part del nivell d'educació de la població. La promoció de la salut, i en particular l'educació en temes de salut, es pot emprendre a través de diferents mitjans: campanyes publicitàries, campanyes als centres de salut, actuacions d'ONGs, actuacions des dels ajuntaments, etc. No obstant això, el que més impacte tindrà en els ciutadans, a mitjà i llarg termini, per la seva capacitat d'harmonitzar i interioritzar les conductes des dels primers nivells educatius, és el portat a terme a través d'un procés programat d'ensenyament $\mathrm{i}$ aprenentatge en el medi escolar, que és el que anomenem educació per a la salut. Les altres actuacions de promoció de la salut poden ser complementàries i útils a curt termini.
El nostre treball s'ha centrat en l'alimentació, un dels capítols bàsics dels programes d'educació per a la salut, ja que nombrosos estudis apunten a un creixent augment de malalties relacionades amb els estils de vida, conseqüència d'una conducta poc saludable en allò que fa referència als hàbits alimentaris (MONTEIRO, 1996). La societat occidental és víctima de múltiples patologies relacionades amb aquests hàbits poc adients, tals com l'obesitat, la diabetis mellitus (excés de glucosa a la sang, que en determinats casos està provocat per l'obesitat) la hipertensió arterial, els problemes cardiovasculars, els problemes traumatològics, el càncer, etc., que es podrien haver evitat amb un programa educatiu.

L'educació per a la salut no tindrà incidència en aquells casos derivats de factors genètics o de malalties no derivades dels estils de vida. És el que entenem com els factors biològics d'una població, sobre els quals tindrà molta més incidència una política de prevenció adient. Els estudis portats a terme per Lalonde (SALLERAS, 1990) van posar de manifest que entre els quatre determinants de la salut, els estils de vida d'una població són el determinant que més impacte té sobre la salut d'aquesta població, per damunt del medi ambient, dels sistemes d'assistència sanitària i dels factors biològics. La importància de l'educació per a la salut a les escoles ja es va posar de manifest mitjançant una resolució del "Consejo Europeo de Ministros de Educación" de 23 de novembre del 1988. En aquesta resolució, l'educació per a la salut és considerada com un procés que utilitza formes programades d'aprenentatge per tal de permetre als individus que prenguin decisions fonamentades, relatives a les qüestions lligades a la salut, i que hi actuïn en conformitat (NATÁRIO, 1993).

Hem pogut constatar, a través de la pròpia experiència i d'autors com Mariscal (1998) i Del Carmen (1998), que moltes idees existents en la població sobre l'alimentació estan lligades a tradicions i idees populars, influenciades per l'ambient, i que no coincideixen, moltes 


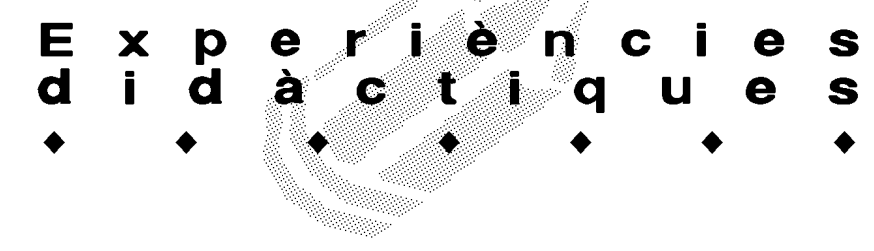

vegades, amb les concepcions modernes de la ciència, i que en la majoria d'ocasions s'acosten a conceptes que poden portar a estils de vida no saludables.

\section{L'aprenentatge constructivista i les idees prèvies}

Aques fet que s'acaba d'indicar ens porta a considerar el constructivisme (DRIVER, 1988) com el marc teòric idoni a l'hora d'abordar tècniques d'intervenció a l'escola, atesa la gran quantitat de conceptes no coincidents amb la versió actual de la ciència (diem actual perquè les idees científiques també canvien amb el temps: recordem com fa pocs anys les sardines es desaconsellaven per a la prevenció de les malalties cardiovasculars, mentre que actualment es consideren beneficioses).

En l'aprenentatge de conceptes, els alumnes tenen les pròpies concepcions sobre allò que se'ls ensenyarà. Aquests esquemes mentals previs són els que utilitzen per interpretar allò que se'ls està ensenyant, i interfereixen de manera decisiva en l'adquisició dels conceptes científics. El problema s'accentua per la persistència d'aquestes idees, que són molt difícils de canviar pels procediments tradicionals d'ensenyament i aprenentatge, ja que habitualment tornen a sortir al postensenyament. Aquestes idees, segons Pozo (1996), són fruit de diversos factors, com l'experiència viscuda en contacte amb el món que ens envolta, les observacions de la vida quotidiana, els llibres de text i altres materials utilitzats a l'escola, la interacció entre el llenguatge científic i el llenguatge quotidià, les intervencions del professor i del context escolar i la influència de la cultura de la societat on es viu.

Des de la perspectiva constructivista, sempre que s'intenta entendre o donar significat a quelcom, es parteix d'una idea o coneixement previ que ja es té, i els nous coneixements es construeixen de forma activa, relacionant la nova informació amb les idees que ja es tenen. En el cas de l'alimentació, moltes de les idees alternatives de l'alumnat estan fortament interioritzades i són molt resistents al canvi, ja que s'han anat formant gradualment des de la infància, fruit del propi raonament i esforç dels alumnes, però seguint dreceres que els han portat a conceptes no coincidents amb els de la ciència actual.

Per al professor és fonamental conèixer les idees prèvies dels alumnes abans de començar a treballar en qualsevol tema, ja que els nous aprenentatges han de partir de les idees que ja tenen. El procés d'intervenció constructivista requerirà el canvi i la reeestructuració o evolució d'aquestes idees, en aquest cas molt lligades a la cultura popular, de forma que les noves construccions mentals siguin al més pròximes possible a les idees de la ciència. De la mateixa manera que les idees alterna- tives s'han generat de forma lenta i gradual per un procés personal i social, la seva transformació també serà un procés actiu i gradual de maduració i interiorització, on influiran aspectes personals i socials. Un ensenyament transmissiu que intenti traslladar a l'alumne "raonaments en préstec" aliens a ell, podrà aconseguir un aprenentatge memorístic, però tindrà poc èxit en la transformació de les idees alternatives.

\section{Antecedents i objectius del treball}

L'objectiu del treball que aquí presentem és conèixer les idees d'un grup d'alumnes portuguesos de 5è i 6è grau (11 i 12 anys), sobre temes relacionats amb l'alimentació.

A Portugal l'alimentació és un tema que rep atenció per part dels investigadors, més pels seus efectes sobre el rendiment escolar que no pas per les idees alternatives o per les metodologies d'aprenentatge. Un antecedent d'investigació a Portugal sobre les idees dels alumnes de 6è any sobre el tema de l'alimentació és el treball de Duarte (2002), en el qual també es realitza una proposta d'intervenció pedagògica. En aquest treball s'indica que els alumnes rebutjaren alguns menjars amb arguments del tipus "conté molt greix", "té poques vitamines" o "no són saludables". En una situació de postensenyament, augmentà el nombre d'alumnes que rebutjaren menjars que contenien refrescos, salsitxes, hamburgueses i xocolata. Fora del context portuguès existeixen altres treballs, com el de Szponar i Stos (1997), que realitzaren un treball d'investigació a Polònia sobre el nivell de coneixement al voltant dels aliments i de la nutrició en nens d'Ensenyament Primari i Secundari. En aquest estudi es va verificar que el nivell de coneixement sobre els principis d'un menjar correcte i sobre els procediments de cuinar i emmagatzemar els aliments és bastant baix a tots els nivells dels ensenyaments.

\section{Metodologia emprada}

L'estudi es realitzà amb els alumnes de tres escoles, de 5è i 6è any (nens i nenes d'11 i 12 anys) de segon cicle d'Ensenyament Bàsic de l'entorn de la ciutat de Beja, a Portugal. La mostra final la configuraren 129 alumnes de set classes de 5è i 115 alumnes de set classes de 6è any. Vam elegir alumnat de dos cursos seguits per poder comparar i seguir la seva evolució conceptual. El tema de l'alimentació s'estudia a 6è. I el nostre objectiu era comparar les idees dels alumnes de 5 è, que no havien estudiat el tema, amb els de 6è, després de l'ensenyament de l'alimentació (postensenyament). Això ens permetria detectar la persistència d'alguns conceptes.

En aquesta fase la metodologia d'investigació és 


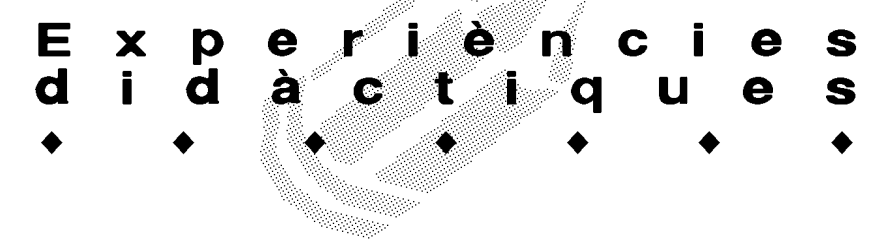

fonamentalment quantitativa, encara que, com en altres investigacions (MELLADO, 1999), optàrem per la combinació de mètodes diversos en funció del problema de la investigació. El principal instrument utilitzat per a la recollida de dades va ser el qüestionari, compost per 21 preguntes escrites, entre obertes i tancades. El qüestionari es va validar prèviament, en diverses etapes, amb un grup d'alumnes ( 5 de 5 è i 5 de 6 è). Amb posterioritat a la resposta del qüestionari, es realitzà una entrevista a alguns dels alumnes per tal de clarificar alguns dubtes derivats de la interpretació quantitativa dels qüestionaris.

\section{Resultats obtinguts}

En aquest article hem seleccionat aquells resultats més íntimament relacionats amb els conceptes d'aliment i de nutrient, incidint en conceptes d'actualitat en educació per a la salut. Els resultats complets de la investigació es poden trobar a Martins (2003).

\section{El Paper dels Aliments}

Les respostes obtingudes a la qüestió 1 (pregunta oberta): En la teva opinió, per a què serveixen els aliments?, es troben a la taula 1. Un cop analitzats els resultats, s'observa que els alumnes no tenen ben definit per a què serveixen els aliments, ja que un percentatge alt diu que aquests serveixen per a alimentar-nos 0 donen idees similars. A 6è tenen una certa inclinació a entendre els aliments com un mitjà per a proporcionarnos energia i nutrients. Els alumnes formulen conceptes associats només a una determinada funció dels aliments; mai expressen més d'una funció a les seves respostes. Ho associen a la supervivència, a la profilaxi de les malalties, a proporcionar-nos vitamines, etc. De fet esperàvem trobar idees més globalitzadores, que expressessin amb les seves paraules que els aliments serveixen

\begin{tabular}{|c|c|c|}
\hline Resposta & $\% 5 \dot{~}$ & $\% 6 \dot{e}$ \\
\hline 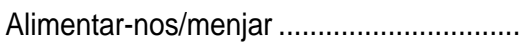 &. .52 & 37 \\
\hline 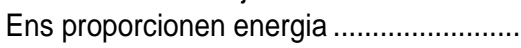 &. .3 & 24 \\
\hline 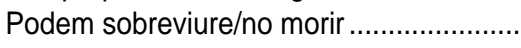 &. .13 & 4 \\
\hline 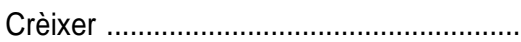 & .. 7 & 6 \\
\hline 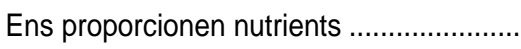 & .. $\quad-$ & 13 \\
\hline 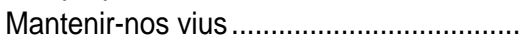 & 4 & 6 \\
\hline 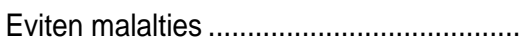 & 5 & 3 \\
\hline 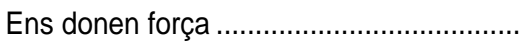 & 5 & 1 \\
\hline 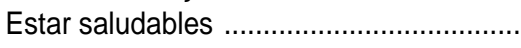 & 2 & 3 \\
\hline 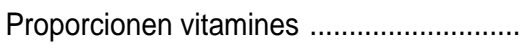 & 4 & 1 \\
\hline Posar-nos forts & 2 & 1 \\
\hline Ens mata la gana & 1 & 1 \\
\hline 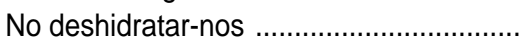 &. .1 & - \\
\hline Ens fa guanyar pes & .. 1 & - \\
\hline
\end{tabular}

Taula 1. Percentatge de respostes donades a la qüestió 1: ¿Per a què serveixen els aliments? per a subministrar els nutrients que ens proporcionen energia i la matèria primera per a l'organisme.

IDENTIFICACIÓ D'ALIMENTS I DE NUTRIENTS

Les respostes a les qüestions 2: Dels termes que segueixen, indica amb una " $X$ " els que consideris aliments, i 3: Dels termes que segueixen, indica amb una " $X$ " els que consideris nutrients (preguntes tancades), s'han agrupat a la taula 2.

Per analitzar els conceptes d'aliment i de nutrient ens hem basat en els criteris d'autors com Mataix (1995) i Cañal (1997). El primer és un estudiós de l'alimentació des del punt de vista científic, mentre que el segon ha realitzat treballs des del punt de vista de la didàctica de les ciències.

Per aliment entenem qualsevol tipus de substància existent al medi (sòlida, líquida o gasosa) de la qual podem obtenir nutrients. Per tant l'aire (conjunt de gasos) i l'aigua natural (aigua, gasos i sals minerals) s'han de considerar aliments, igual que els teixits que prenem dels animals, dels vegetals, de les algues i dels fongs. $\mathrm{Hi}$ ha aliments no energètics, com l'aigua de l'aixeta,

\begin{tabular}{|c|c|c|c|c|}
\hline \multirow[b]{3}{*}{ Descripció } & \multicolumn{4}{|c|}{$\begin{array}{l}\text { Percentatge d'alumnes } \\
\text { que ho consideren un }\end{array}$} \\
\hline & \multicolumn{2}{|c|}{ aliment } & \multicolumn{2}{|c|}{ nutrient } \\
\hline & $5 \dot{e}$ & $6 \dot{e}$ & $5 \dot{e}$ & $6 \dot{e}$ \\
\hline Glúcids (Hidrats carboni) ... & 1,55 & 4,35 & 62,79 & 83,48 \\
\hline 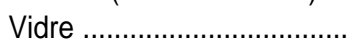 & 1,55 & 2,61 & 29,46 & 6,09 \\
\hline $\mathrm{Pa}$ & 93,02 & 94,80 & 6,20 & 5,20 \\
\hline Metall ............................... & 2,33 & 1,74 & 26,36 & 6,96 \\
\hline 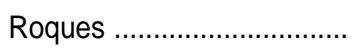 & 2,33 & 3,48 & 27,13 & 6,96 \\
\hline 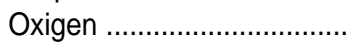 & 6,20 & 4,35 & 36,43 & 20,00 \\
\hline Oli d'oliva ................................... & 69,77 & 64,35 & 13,18 & 13,04 \\
\hline 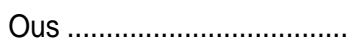 & 91,47 & 95,50 & 6,20 & 4,34 \\
\hline 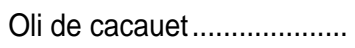 & 50,39 & 37,39 & 24,03 & 11,30 \\
\hline 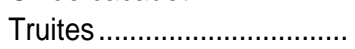 & 85,27 & 90,43 & 8,53 & 4,35 \\
\hline Xocolata .................. & 71,32 & 66,96 & 8,53 & 5,22 \\
\hline 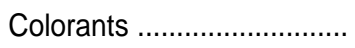 & 20,16 & 15,65 & 37,98 & 39,13 \\
\hline 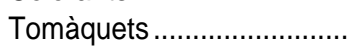 & 92,25 & 95,12 & 4,65 & 4,85 \\
\hline 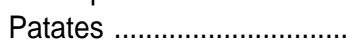 & 92,25 & 96,15 & 5,43 & 3,85 \\
\hline 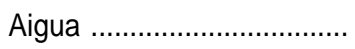 & 61,24 & 53,91 & 12,40 & 10,43 \\
\hline Aire ………............................... & 7,75 & 5,22 & 34,11 & 12,17 \\
\hline 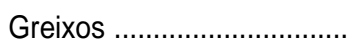 & 25,58 & 19,13 & 31,78 & 40,00 \\
\hline 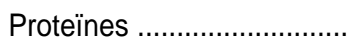 & 18,60 & 9,57 & 64,34 & 78,26 \\
\hline Peix & 93,80 & 98,26 & 4,65 & 1,73 \\
\hline 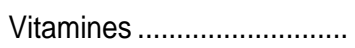 & 36,43 & 8,70 & 63,57 & 77,39 \\
\hline 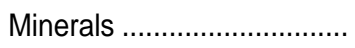 & 21,71 & 6,09 & 49,61 & 71,30 \\
\hline 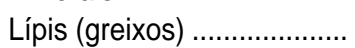 & 8,53 & 5,22 & 65,89 & 80,00 \\
\hline 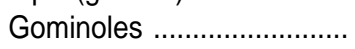 & 57,36 & 52,17 & 8,53 & 4,35 \\
\hline 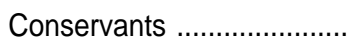 & 14,73 & 12,17 & 48,84 & 33,04 \\
\hline Fibres & 20,93 & 14,78 & 51,94 & 71,30 \\
\hline
\end{tabular}

Taula 2. Percentatge de respostes donades a les qüestions 2 i 3 


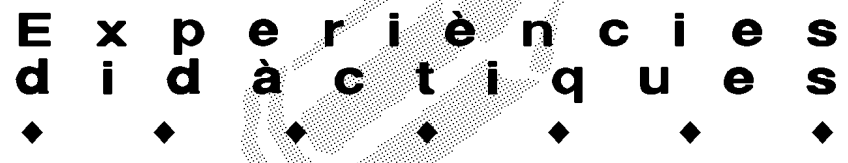

que ens proporciona aigua i sals minerals (nutrients inorgànics), i aliments energètics (pernil, ou, pa, fruita, etc.), que tant ens aporten nutrients orgànics (glúcids, lípids, preteïnes, vitamines) com inorgànics (aigua i sals minerals), així com altres substàncies no nutritives com la fibra dietètica (cel-lulosa, per exemple).

Nutrient és tota substància que obtenim dels aliments per proporcionar-la a les cèl-lules. Són metabolitzats per proporcionar-nos energia i matèries primeres per al creixement, el manteniment i la restauració d'òrgans i teixits. Sota aquest punt de vista l'oxigen és un nutrient, igual que l'aigua pura, les sals minerals, els lípids, els glúcids, les proteïnes i les vitamines.

La fibra dietètica, en no ser absorbida als intestins $i$, per tant, no metabolitzada, no és un nutrient, de la mateixa forma que no ho són molts conservants i colorants.

Des d'aquesta perspectiva l'alimentació està sotmesa a influències externes, com les educatives, culturals $\mathrm{i}$ econòmiques $i$, per tant, es pot modificar de forma voluntària i conscient. $\mathrm{Hi}$ intervenen processos com la recerca d'aliment, la seva elecció i preparació. Per tant, hi influeixen factors sensorials i simbòlics, que entren de ple en els continguts de l'educació per a la salut.

La nutrició comprèn els processos de digestió, absorció, transport i metabolisme dels nutrients. Per això, llevat del mastegar, tots són processos inconscients i involuntaris i, per tant, no educables. No obstant això, amb l'elecció dels aliments (en qualitat i quantitat) i indirectament dels nutrients que contenen, podem evitar malalties derivades del metabolisme, com l'arterioesclerosi, determinada, en gran part, per la selecció d'aliments amb diferents tipus d'àcids greixosos.

Analitzant les dades de la taula 2 s'observa que alguns aliments com el pa, ous, truites, tomàquets, patates i peix són identificats bé, tant a 5 è com a 6è, encara que en el cas de la truita existeix una lleugera diferència entre 5è i 6 è. És evident que no existeix una idea alternativa. No obstant això, quan es tracta de l'oli d'oliva, de l'oli de cacauet, i de la xocolata, ja no són identificats d'una forma tan clara. Fins i tot baixa el percentatge de resposta correcta a 6è (postensenyament).

La majoria no identifica l'aigua com un aliment, i baixa també el percentatge a 6è. Tampoc l'aire no es contempla com un aliment. El percentatge és baixíssim, i disminueix també a 6è, i més aviat és identificat con a nutrient.

Tot seguit analitzem els nutrients. Els glúcids i les proteïnes són identificats per un $62,79 \%$ i $64,34 \%$ d'alumnes a 5è, mentre que a 6è pugen al $84,34 \%$ i $78,26 \%$ respectivament, però en cap dels dos casos la seva identificació és tan bona com en el cas dels aliments (pa, ous o patates). Quelcom semblant succeeix amb les vitamines, destacant, en aquest cas, que el $36,43 \%$ dels alumnes de 5 è les identifiquen com a aliments.

Una dada significativa és que els greixos només són identificats com a nutrients pel $31,78 \%$ a 5 è i pel $40 \%$ a 6è. Quan se centren en l'opció "lípids (greixos)", els percentatges augmenten fins als valors amb els quals identificaren els glúcis i les proteïnes, indicant la presència d'una idea alternativa. També s'aprecia una idea alternativa en el cas de l'oxigen, ja que el percentatge disminueix del $36,43 \%$ a 5 è fins al $20 \%$ de 6 è. Els estudis tradicionals sobre l'alimentació no faciliten la idea que un gas sigui considerat com a nutrient. El gas s'estudia a la respiració, però en aquest context no es tracta com un nutrient, sinó com un gas que es necessita per a la respiració. Al ser temes diferents, generalment no existeix relació entre ells ni en els llibres de text ni en altres materials escolars. Per altra banda, es tendeix a associar l'aliment amb els sòlids que proporcionen energia.

Els minerals són seleccionats per un percentatge baix, encara que el seu nombre augmenta del $49,61 \%$ de 5 è al $71,3 \%$ de 6 è, malgrat que caldria esperar un valor més alt a 6è, ja que aquest aspecte s'ha tractat de forma extensa durant el curs. Destaquem el cas dels conservants, ja que, malgrat no ser nutrients, són reconeguts com a tals pel $48,84 \%$ a 5 è i pel 33,04\% a 6 è.

Sobre el fet que un elevat nombre d'alumnes de 5 è considerin el metall com un nutrient, val a dir que, a l'entrevista final, alguns alumnes indicaren que van contestar així perquè el ferro és un metall, i els aliments contenen ferro.

El PAPER de les Fibres

Referent a les qüestions 4 ( $P$ el que fa a les fibres, indica la/les opcióls correctales) i 5 (Segons la teva opinió, per què les fibres són importants per a la nostra alimentació?), les respostes donades s'indiquen a les taules 3 i 4, respectivament.

La fibra té, actualment, gran importància per al còlon, sempre que sigui en quantitats adients, ja que un excés pot resultar perjudicial per a la salut (MATAIX, 1995). Detectem, novament, una idea alternativa (taula 3), fàcil d'aquirir, atesa la discrepància existent entre els autors a l'hora de denominar-la. Si ens atenem al concepte de nutrient, la fibra forma part dels aliments, però no es pot considerar un nutrient, ja que no s'absorbeix a cap tracte de l'intestí, i per tant no es metabolitza. Encara que existeixen textos escolars que consideren la fibra con un nutrient, la qual cosa reforça la idea alternativa, actualment es considera que no tots els components d'un aliment són nutrients, per exemple els colorants. 


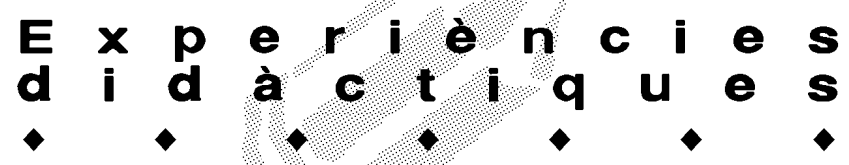

\begin{tabular}{|c|c|c|}
\hline Afirmació & $\% 5 \dot{e}$ & $\% 6 \dot{e}$ \\
\hline - Les fibres són un aliment. & 17 & 11 \\
\hline - Les fibres són un nodrient utilitzat pel & 36 & חר \\
\hline . Les fibres no són un nutrient perquè no & 36 & 29 \\
\hline són absorbides per l'organisme ........................... & 16 & 5 \\
\hline - Les fibres són un nodrient perquè són & & \\
\hline - Les fibres regulen el moviment dels & & \\
\hline intestins i la quantitat d'aigua a l'intestí ............ & 10 & 37 \\
\hline
\end{tabular}

Taula 3. Percentatge de respostes donades a la qüestió 4: $\mathrm{Pel}$ que fa a les fibres, indica la/les opcióls correctales

Actualment, a l'intestí no se'l considera una part interna de l'organisme, encara que hi tingui lloc el procés de la digestió (tots els éssers vius digereixen externament). La diferència entre els colorants i la fibra és que els colorants no tenen cap funció a l'organisme, només la de crear en els aliments un aspecte agradable i mengívol; en canvi, la fibra sí que té funcions beneficioses en el còlon per a l'organisme: per exemple, facilitar la mobilitat al tracte intestinal, la qual cosa té una funció preventiva del càncer de còlon.

Analitzant la taula 3 podem apreciar la confusió general que existeix tant en alumnes de 5è com en els de 6è, detectant-se la idea alternativa que la fibra és un nutrient. Així mateix, sorprèn el baix percentatge $(5 \%)$ d'alumnes de 6è (postensenyament) que consideren que les fibres no són un nutrient perquè no són absorbides per l'organisme. El percentatge d'alumnes que pensen que les fibres regulen el moviment intestinal $i$ la quantitat d'aigua continguda (taula 3) augmenta en el cas de 6è, però encara és un valor baix (37\%), per la qual cosa no s'ha produït una evolució conceptual significativa.

$\mathrm{Hi}$ ha molts alumnes, especialment de 5 è, que fan l'afirmació: "les fibres són importants perquè donen força al nostre cos" (taula 4). És possible que l'afirmació es degui al fet d'associar les fibres a quelcom útil, i la força a un benefici. Com que associen els dos conceptes de

\begin{tabular}{|c|c|c|}
\hline Afirmació & $\% 5 \dot{e}$ & $\% 6 \dot{e}$ \\
\hline - Les fibres són un aliment. & 17 & 11 \\
\hline - Perquè donen força al nostres cos ....... & 39 & 25 \\
\hline - Perquè és important menjar una mica de tot ........... & 26 & 17 \\
\hline 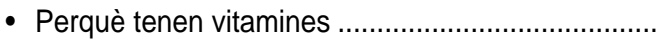 & 24 & 13 \\
\hline - Perquè regulen el moviment a través de & & \\
\hline l'intestí gros així com l'absorció d'aigua ..................... & 36 & 31 \\
\hline - Perquè ens proporcionen molta energia .................. & 32 & 32 \\
\hline
\end{tabular}

Taula 4. Percentatge de respostes donades a la qüestió 5: Segons la teva opinió, per que les fibres són importants per a la nostra alimentació? forma positiva, han considerat l'afirmació com a vertadera.

Esperàvem que un major percentatge d'alumnes, en especial de 6è, consideressin com a vertader el fet que les fibres regulen els moviments intestinals i l'absorció d'aigua, però no hi va haver grans diferències entre els de 5 è i els de 6è. I fins i tot es va provocar una baixada en aquests últims. Un cop més apreciem com persisteixen les idees (no oblidem que els alumnes de 6è van estudiar amb cert aprofundiment el paper dels components dels aliments en l'organisme). La situació obtinguda indica clarament que els alumnes no reconeixen el veritable paper de les fibres en l'alimentació, i només tenen la noció que són importants.

El PAPER de L'Aigua

Les respostes obtingudes a la qüestió 6 (oberta): Consideres que l'aigua és un aliment? Per què?, s'indiquen a les taules 5,6 i 7.

La principal idea que es dedueix de les taules 5, 6 i 7 és que hi ha bastants alumnes que tenen el concepte que l'aigua no és un aliment. La idea clarament expressada a les justificacions és que l'aigua és una beguda, $i$ no un aliment. Durant l'entrevista es va comprovar que

\begin{tabular}{|c|c|c|}
\hline Resposta & $\% 5 \dot{e}$ & $\% 6 \dot{e}$ \\
\hline $\mathrm{Si}$ & 52 & 33 \\
\hline 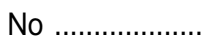 & 39 & 42 \\
\hline Sense resposta & 9 & 25 \\
\hline
\end{tabular}

Taula 5. Percentatge de respostes donades a la qüestió 6 : Consideres que l'aigua és un aliment?

molts alumnes lliguen els aliments a la matèria en estat sòlid $i$ al fet que proporcionen energia. Només entenen l'aigua com a necessària per a la nostra vida, i es veu més com una cosa per a treure la set $i$ evitar la deshidratació. Cal destacar que hi ha més alumnes de Gè que no consideren l'aigua com aliment, malgrat haver estudiat el tema de l'alimentació. És una nova idea alternativa que es veu reforçada pel fet de no estar inclosa en la roda dels aliments, i és un exemple de com les idees alternatives, a banda de consolidar-se per les percepcions relacionades amb el món sensorial, poden ser reforçades pels mateixos materials escolars. És un cas típic d'idea consolidada a través de les percepcions sensorials. Habitualment satisfem la nostra fam amb aliments sòlids. Igual que amb l'aire no satisfem la gana, amb l'aigua només satisfem la set. La percepciò sensorial facilita el fet de considerar "aliment" el que és sòlid i no allò que és líquid o gasós, malgrat que ens alimentem amb una sopa.

A les taules 6 i 7 es detallen els raonaments donats pels alumnes per justificar les seves respostes, que són 


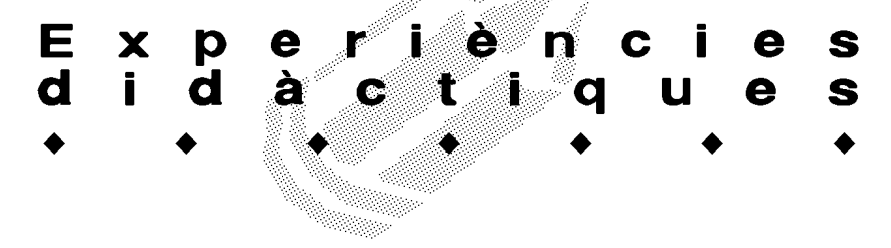

dignes de tenir en compte per un professor a l'hora d'organitzar les seves classes.

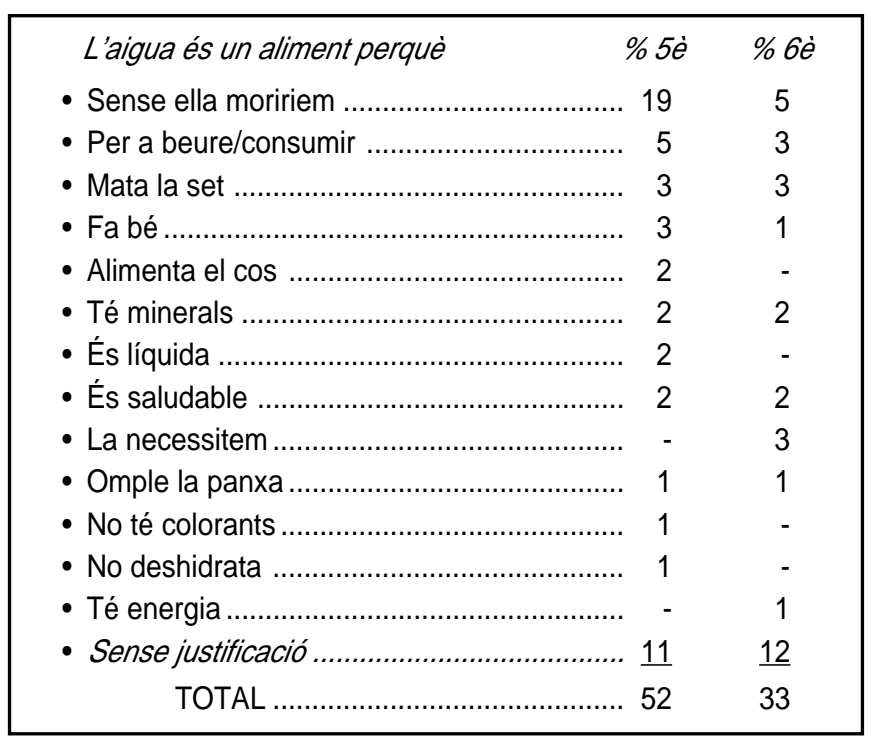

Taula 6. Justificació donada pels alumnes que consideren l'aigua com un aliment

El PAPER deLs GReixos

Finalment, la qüestió 7 (tancada): Pel que fa als greixos (lípids), indica lalles opciólns correctales, va donar els resultats que es mostren a la taula 8. Analitzant les dades d'aquesta taula, podem apreciar que existeix

\begin{tabular}{|c|c|c|}
\hline L'aigua no és un aliment perquè & $\% 5 \dot{e}$ & $\% 6 \dot{e}$ \\
\hline • És per a beure & 8 & 12 \\
\hline - Només mata la set & 4 & 5 \\
\hline - No té nutrients & 5 & 1 \\
\hline • No es menja & 2 & 2 \\
\hline 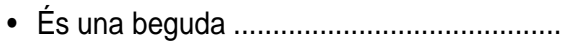 & 2 & 2 \\
\hline 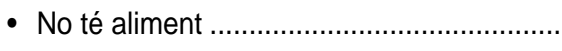 & 2 & 2 \\
\hline 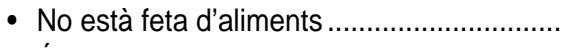 & 2 & 1 \\
\hline • És un líquid & 3 & - \\
\hline - No té sabor & - & 3 \\
\hline 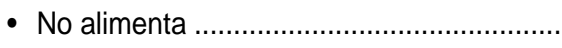 & - & 2 \\
\hline 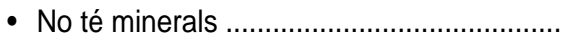 & - & 2 \\
\hline - No té vitamines & 1 & - \\
\hline 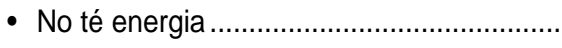 & - & 1 \\
\hline 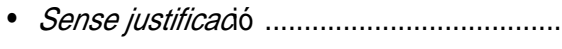 & $\underline{8}$ & $\underline{9}$ \\
\hline TOTAL & 37 & 42 \\
\hline
\end{tabular}

Taula 7. Justificació donada pels alumnes que no consideren l'aigua com un aliment

molta confusió en el paper que juguen els greixos davant la salut, ja que cap de les opcions elegides assoleix un percentatge gaire elevat. Aproximadament el $40 \%$ dels alumnes d'ambdós anys escolars considera que l'oli d'oliva és un dels millors aliments greixosos. Aquesta idea és concordant amb el que actualment es considera a la societat, tant espanyola com portuguesa. És una idea extraescolar que és palesa en els alumnes, i coincideix amb l'opinió actual de la ciència. Contrasten amb aquesta opinió els percentatges assolits: $56 \%$ a 5 è i $42 \%$ a 6 è, que opten per l'opció que tots els aliments greixosos són dolents per al sistema circulatori.

Alguns àcids greixosos abundosos a la carn, llet, oli de coco i de "palmiste", aquests dos últims vegetals (no tot el que és vegetal és saludable), quan es consumeixen en excés són els responsables, conjuntament amb els alts nivells de colesterol, del deteriorament dels vasos sanguinis, consistent en la formació de plaques d'atero-

\begin{tabular}{|c|c|c|}
\hline Afirmació & $\% 5 \dot{e}$ & $\% 6 \dot{e}$ \\
\hline $\begin{array}{l}\text { - L'oli d'oliva és un dels millors aliments } \\
\text { areixosos }\end{array}$ & 38 & 41 \\
\hline $\begin{array}{l}\text { - Tots els aliments geixosos són dolents, } \\
\text { ja que ens engreixen }\end{array}$ & 41 & 24 \\
\hline $\begin{array}{l}\text { - Tots els aliments greixosos fan mal } \\
\text { al sistema circulatori (cor) ................. }\end{array}$ & 56 & 42 \\
\hline $\begin{array}{l}\text { - Hem de menjar una mica de tots els } \\
\text { greixos, en les quantitats adients a les }\end{array}$ & & \\
\hline nostres necessitats ....................... & 41 & 54 \\
\hline $\begin{array}{l}\text { - Hi ha uns greixos que hem de menjar } \\
\text { més que uns altres. Però tots ells són }\end{array}$ & 36 & 32 \\
\hline $\begin{array}{l}\text { - La mantega és un aliment millor que les } \\
\text { margarines vegetals, perquè els seus } \\
\text { greixos no són alterats industrialment ................. }\end{array}$ & 33 & 21 \\
\hline
\end{tabular}

Taula 8. Percentatge de respostes obtingudes a la qüestió 7: $P e l$ que fa als greixos (lípids), indica lales opciólns corectales

ma, que, a més de contribuir a la rigidesa dels vasos, acaben per obstruir-los i produir infarts. Aquest tipus d'àcids greixosos, igual que el colesterol, són components fisiològics necessaris per a l'organisme, i la seva perillositat ve provocada pel seu excés, i no quan estan en quantitats adients. Altres àcids greixosos presents a l'oli d'oliva (àcid oleic) i al peix (àcids greixosos omega-3) no són dolents per al sistema circulatori, sinó que són beneficiosos. L'àcid oleic disminueix els nivells de colesterol total $i$, en el cas que els teixits continguin un excés de colesterol, també afavoreix la disminució del seu nivell. L'àcid oleic tembé dificulta la formació de plaques d'ateroma. Els àcids greixosos omega-3 produeixen vasodilatació i disminució de l'agregació plaquetària a les plaques d'ateroma, per tant tenen un efecte beneficiós sobre l'arterioesclerosi. 


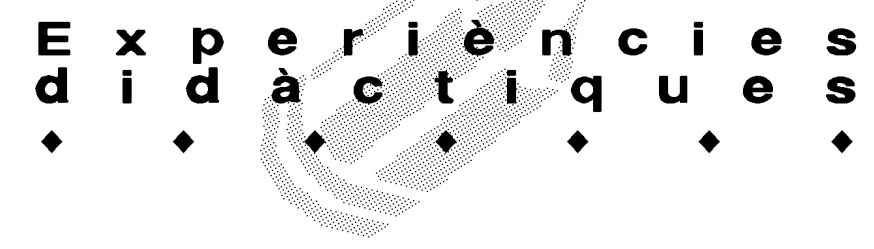

Les opcions 4a i 5 a de la taula 8, ambdues correctes, han estat elegides de forma desigual a cada curs. El $54 \%$ d'alumnes de 6 è que trien l'opció 4 (davant el $41 \%$ de 5è) mostra un lleuger canvi conceptual, però resulta un percentatge relativament baix. Crida l'atenció el fet que, en ambdós cursos, l'opció 5 mostra uns percentatges d'elecció inferiors als de la 4.

Aquesta inestabilitat i confusió de conceptes és típica de la presència d'idees alternatives. A la societat existeix l'opinió que tot el que sigui greix engreixa i és dolent, però l'oli d'oliva va adquirint "bona premsa". Aquesta influència cultural és el que possiblement origina la confusió en els alumnes, on observem l'estabilitat i permanència d'aquestes idees, ja que els de 6è, malgrat haver estudiat aquestes qüestions, no destaquen significativament per un procés d'evolució conceptual.

\section{Conclusions}

El qüestionari formulat als alumnes demostra que no existeix una marcada evolució conceptual, i indica clarament que els conceptes apresos, encara que els serviren per superar l'avaluació formal, es van assimilar d'una forma mecànica i memorística. Destaquem també que les experiències quotidianes i els valors culturals tenen més importància, en allò referent a les concepcions dels alumnes, que els continguts escolars. També es posa de manifest que els alumnes valoren més els aspectes qualitatius dels aliments que els quantitatius, i que tendeixen a simplificar les seves concepcions sobre els aliments.

Dels resultats obtinguts destaquem les següents conclusions específiques respecte a les idees dels alumnes:

- No han assimilat un concepte clar sobre el que és l'alimentació. Més aviat l'associen a aspectes parcials, que molt sovint no es deuen a l'alimentació.

- Els de 6è curs, en situació de postensenyament, valoren especialment el paper dels aliments com a fornidors d'energia, i identifiquen millor els nutrients.

- En general, els nutrients els entenen més com a constituents dels aliments que no pas pels seus efectes en la nutrició.

- Tant a 5è com a 6è hi ha un percentatge baix d'alumnes que consideren l'oxigen com a nutrient, però és més alt l'obtingut a 5 è que a 6 è.

- Molts alumnes identifiquen les fibres com a nutrients, i a més diuen que proporcionen energia.

- Els colorants i conservants es consideren, majoritàriament, com a nutrients.

- Hi ha una confusió generalitzada sobre el paper de l'aigua. També tenen indecisió en la classificació com a aliment o nutrient.
- Destaquen els que consideren que aliment només és allò que és sòlid i que es pot mastegar. Per tant, no identificaren l'aigua com un aliment sinó com una beguda, fent una distinció entre aliment $\mathrm{i}$ beguda. Aquesta situació és més accentuada en els de 6 è.

- Tant els de 5è com els de 6è entenen, en un percentatge elevat, que tots els aliments que contenen greixos són dolents per a la salut.

\section{Referències bibliogràfiques}

CAÑAL, P. La fotosíntesis y la "respiración inversa" de las plantas: ¿un problema de secuenciación de los contenidos? «Alambique», 14 (1997) 21-36.

DEL CARMEN, L. Educación para la salud y hábitos alimentarios en la formación inicial del profesorado de Educación Infantil y Primaria. En E. Banet y A. de Pro (Eds.): Investigación e Innovación en la Enseñanza de las Ciencias. Vol. 1. Ed. Diego Marín. Murcia. 1998. Pàgs. 188-195.

DRIVER, R. Un enfoque constructivista para e/ desarrollo del currículo en ciencias. «Enseñanza de las Ciencias», 6,2 (1988) 109-120.

DUARTE, M.C. Alimentação humana: Proposta e avaliação de uma intervenção pedagógica no $6^{\circ}$ ano de Escolaridade. Ed. Instituto de Educação e Psicologia. Universidade do Minho. Braga. 2002.

MARISCAL, C. Cien errores de la nutrición. Ediciones Temas de hoy. Madrid. 1998.

MARTINS, V. Las ideas alternativas sobre la alimentación de los alumnos de 5o y 6o año. Trabajo de investigación inédito para la obtención de Diploma de Estudios Avanzados. Universidad de Extremadura. 2003.

MATAIX, J. i CAZO, E. Nutrición para Educadores. Ed. Díaz de Santos. madrid. 1995.

MELLADO, V., BLANCO, L. i RUIZ, C. Aprender a enseñar ciencias experimentales en la Formación inicial del profesorado. Estudios de casos sobre la enseñanza de la energía. Ed. ICE Universidad de Extremadura. Badajoz. 1999.

MONTEIRO, C.A., MONDINI, L. i COSTA, R.B.L. Mudanças na composição e adequação nutricional da dieta familiar nas áreas metropolitanas do Brasil (1988-1996). «Saúde Pública», 34,3 (1996) 251-258.

NATÁRIO, E. Escola Promotora de Saúde. Conceitos e princípios de Intervenção. Promover a Saúde na Escola. Texto de Apoio 1/93. Ed. Direcção de Serviços de Saúde Escolar e Ocupacional Núcleo de Saúde escolar. Direcção-Geral de Saúde. Lisboa. 1993.

POZO, J.I. Las ideas del alumnado sobre la ciencia: de dónde vienen, a donde van... y mientras tanto qué hacemos con ellas. «Alambique», 7 (1996) 18-26.

SALLERAS, L. Educación Sanitaria. Ed. Díaz de Santos. Madrid. 1990.

SZPONAR, L. i STOS, K. The level of knowledge on food nutrition among children in elementary and secondary schools. «Polish Journal of Food and Nutrition Science», 7/48, 3 (1997) 555-566. 